\title{
Fans as Transcultural Gatekeepers: The Hierarchy of BTS' Anglophone Reddit Fandom and the Digital East-West Media Flow
}

\author{
Kimery S. Lynch \\ University of Hawaii-Manoa \\ kimery@hawaii.edu
}

Author Biographical Note: Kimery S. Lynch is a master's student in the Asian Studies department at the University of Hawaii-Manoa whose research focuses on K-pop fandom, online communities, and the digital East-West media flow. As a Reddit moderator herself, she is specifically interested in BTS' English-speaking fandom and the effect of moderated platforms on the flow of information into transcultural fandoms.

\begin{abstract}
:
This paper describes how fandom organization on visibly hierarchical social media platforms differs from rhizomatic social media platforms. It discusses how Reddit's hierarchical structure controls the flow of information into digital Anglophone K-pop fandoms, shedding light on this aspect of the East-West transcultural flow. Through analysis of comments and interviews with 8 moderators of the K-pop group BTS' subreddit (/r/bangtan), I show that when certain fans are in a position of power over other fans, they become digital gatekeepers. I argue that by becoming gatekeepers, these fans gain unlimited social capital and use it to control the content seen by the rest of the /r/bangtan community, much like a traditional news gatekeeper. Doing so controls what BTS content $/ \mathrm{r} /$ bangtan users will continue to interact with, perceive, and further spread along this East-West flow. It also demonstrates a user desire for expert curators to filter out "fake news" for them.

Acknowledgements: I would like to express my deep gratitude to Dr. Anna Stirr and Dr. Young-A Park for their patient guidance, enthusiastic encouragement and useful critiques of this research. I am thankful for three anonymous reviewers for providing helpful comments on earlier drafts of this manuscript. I would also like to extend my thanks to the moderators of / $/$ bangtan for providing valuable feedback, as well as my ASAN 750 research seminar class at the University of Hawaii-Manoa for their assistance throughout the writing process.
\end{abstract}

NOTE: This manuscript was published in the journal New Media \& Society on September 30, 2020. This is the accepted manuscript, not the final published PDF. Under SAGE's Green Open Access policy, the accepted manuscript may be shared at any time after your paper is accepted and in any format. Reuse is restricted to non-commercial and no derivative uses. Please cite the final published PDF, and not this paper.

\section{CITATION:}

Lynch, Kimery S. "Fans as Transcultural Gatekeepers: The Hierarchy of BTS' Anglophone Reddit Fandom and the Digital East-West Media Flow." New Media \& Society, (September 2020). https://doi.org/10.1177/1461444820962109. 


\section{Introduction}

In 2017, BTS was the first K-pop group to win an award from a mainstream American award show. In winning, BTS ended Justin Bieber's 6-year streak of winning the "Top Social Artist" award at the Billboard Music Awards (BBMAs). This award means that the winner has the most engaged fans on social media. Notably, BTS, a Korean pop group who sings primarily in Korean, won a major American award in the same year that Luis Fonsi's song "Despacito" became the longest no. 1-charting non-English language song in Billboard history. These transcultural successes amazed the English-speaking public, who was used to only seeing winning acts from traditional Western media capitals (TooFab Staff, 2017).

BTS has continued to win the "Top Social Artist" award every year since 2017, as well as bigger awards at other major American awards shows. This success suggests that the media flows bringing these different transcultural acts are likely to become a more permanent fixture of the Western, Anglophone cultural landscape. This paper focuses on the East-West transcultural flow that is challenging the culturally dominant West-East transcultural flow, with particular attention to K-pop and BTS on hierarchical social media. The key to understanding this flow lies in the very category BTS won: social media.

In order to understand the East-West transcultural flow BTS and K-pop represent, we must first understand social media's role in facilitating the flow itself. Studies of K-pop fandom and social media have extensively discussed its broader role in developing K-pop's Western fandom (Jin, 2018; Jin and Yoon, 2016). Fandom studies scholars have also noted how different social media platforms change how people organize and interact within fandoms (Morris, 2018). Therefore, understanding the East-West transcultural flow that Anglophone K-pop fandom exemplifies means examining how all major forms of social media fandom synthesize to 
facilitate this East-West transcultural flow. In turn, this synthesis requires paying attention to the understudied social media platforms structured differently from Facebook and Twitter (Stoycheff et al., 2017), in particular, explicitly hierarchical social media platforms like Reddit.

In this paper, I describe how a currently popular visibly hierarchical social media platform, Reddit, differs from more "rhizomatic" social media-based fandoms, such as Twitter and Tumblr (Morimoto, 2018: 286). I discuss how the hierarchical structure of Reddit influences the flow of information into digital Anglophone K-pop fandoms to give a more comprehensive picture of the East-West transcultural flow. I do this based on in-depth interviews conducted via the text-based instant messaging service Discord in March 2020 with 8 moderators of the BTS subreddit (/r/bangtan). /r/bangtan is the largest Anglophone BTS-specific forum with over 145,000 subscribed users at the time of writing. I also analyzed public posts made by regular subreddit users interacting with the moderators to further explain the institutional hierarchy of the BTS subreddit. In doing so, I show that when certain fans are in a position of power over other fans, they become digital gatekeepers. I argue that by becoming gatekeepers, these fans gain unlimited social capital and use it to control the content seen by the rest of the /r/bangtan community. The gatekeepers of these hierarchical online communities therefore curate which transcultural products to restrict and allow within their own fan community. Doing so controls what BTS content $/ \mathrm{r} /$ bangtan users will continue to interact with, perceive, and further spread along this East-West flow. It also demonstrates a user desire for expert curators to filter out "fake news" for them.

\section{Background}

Hallyu, or the Korean Wave

The East-West media flow has two main components: the original Eastern media circuits, 
and the crossover to the Western media sphere. K-pop's original Eastern media circuit is Hallyu, or the "Korean Wave," broadly defined as the global popularity and export of Korean popular culture. Hallyu is more than K-pop: it also includes things such as Korean beauty products, Korean e-sports, Korean food, and Korean dramas. Korean dramas began the entire Hallyu phenomenon in China in the 1990s and remained confined to Asia for the first two decades (Shim, 2008: 15). However, by 2008, social media platforms' rising popularity began what communications scholar Dal Yong Jin refers to as "Hallyu 2.0," during which K-pop rather than K-drama began to widely circulate outside of Asia for the first time (Jin, 2016). As social media continues to develop and rise in popularity in the Anglophone world, so does Hallyu and K-pop.

BTS is a K-pop group that has particularly risen to prominence in the Anglophone world through social media. BTS has won international awards, and is known for their vast, international fandom on all popular social media. Although BTS debuted as a group in 2013, it is worth noting they did not perform on American TV until late 2017 at the American Music Awards, after they won the award for "Top Social Artist" at the BBMAs earlier in the year. This timeline means that BTS already accrued a large, US-based fandom before engaging in any standard American media circuits. BTS has continued growing in international popularity as well. According to a report by the Hyundai Research Institute in 2019, BTS generates US \$4.9 billion for the South Korean economy alone each year (for reference, Psy generated US \$844 million with his hit "Gangnam Style" in 2012) (Aurora, 2019; Elberse and Woodham, 2020). BTS' large, social media-based fandom is a relevant case study for understanding the various dynamics within the East-West transcultural flow.

\section{Reddit}

Within the world of social media, this paper focuses on Reddit, a social news aggregation 
and discussion website. Users submit content to the site such as links, text posts, and images, which other users then vote up or down and discuss. Within Reddit, there are separate communities called "subreddits," which house content pertaining to one specific hobby or topic. The subreddit I am studying (/r/bangtan) houses content pertaining to BTS. According to the public results of a $/ \mathrm{r} /$ bangtan census in December 2018, over two-thirds of the $/ \mathrm{r} / \mathrm{bangtan}$ community is between the ages of $18-27,86.4$ percent are female, and 70.7 percent are from Western, Anglophone countries (meaning the US, Canada, the UK, and Australia), with 51 percent from the US alone (BTS Projects Team, 2019). While we can fairly assume that /r/bangtan is dominantly composed of Westerners and native English-speakers from the statistics, some users are not from a native English-speaking or Western country, and those who are might speak English as a second or third language. Thus, while this paper uses the words "Western" and "Anglophone" to describe the subreddit as a whole, we should note that a minority of users who do not fit one or both of these descriptions exist. We should also note that the demographics of the $/ \mathrm{r} /$ bangtan subreddit do not reflect the whole platform of Reddit.

\section{Reddit Moderators}

Like the unique demographics of each subreddit, each subreddit has moderators that create and enforce subreddit-specific rules detailing acceptable content and community comment etiquette. In other words, the moderators control the "quotidian rhythm" of the space (Théberge, 2005), which differs from the hidden, indirect controls of rhizomatic social media via algorithms (Hindman, 2009). Moderators typically create the rules governing the subreddit by "executive fiat," that is, without any user input (Seering et al., 2019: 1435), which is the case in /r/bangtan. Moderators enforce these rules by removing rulebreaking posts and comments and by banning users, again by "executive fiat". When moderators remove posts and comments, they "establish 
a...set of boundaries within which discourse is acceptable," (Squirrell, 2019: 1912). In other words, removing posts allows moderators to gatekeep what is acceptable information for subreddit users to interact with. This is why having moderators distinguishes Reddit as a platform from Twitter or Tumblr. Twitter and Tumblr by design have no official built-in central leadership for each community on the platform, and therefore do not explicitly gatekeep the user's view of the object of fandom.

Moderators are unpaid volunteers that are usually (though not always) selected from within the community through an application process run by the established moderators, differentiating them from paid content moderators on rhizomatic platforms (Gillespie, 2018). The moderators are usually also fans in the community they moderate. The first moderator (or the "top mod") is either the person who created the subreddit, the first to ask Reddit's administrators to become the subreddit's moderator, or the most senior moderator after those above them left. For the junior moderators, during their application process, "head moderators tend to look for members who understand the community's values, have the maturity to set an example, and can enforce the rules appropriately," (Seering et al., 2019: 1423). In /r/bangtan, the aforementioned qualities indicate having the interpersonal skills to act or appear unbiased to the community, the importance of which I will explain in-depth later.

I am a moderator of the BTS subreddit I discuss in this paper, which I mention for transparency and to follow the "aca-fan" tradition of fandom studies. I have been an active member of the /r/bangtan community, and built much of the early culture and community from the ground-up. I created the initial subreddit rules, constructed the standard practice for subsequent moderators, and developed much of the early original content on the subreddit. I helped select all of the current moderators, and I interact with them frequently as a fellow 
moderator and fan online. During my interviews, I emphasized to the moderators that their answers would not affect any of their moderation duties. I do not hold any economic power over the moderators, since moderation is an unpaid, voluntary position. The moderators trusted me more as an academic interviewer because I was a peer, because if I misrepresent their words or actions as a moderator, I would also misrepresent myself. This unique positionality allows me unlimited access to the administrative underbelly of $/ \mathrm{r} /$ bangtan, but it is also a limitation of this study. This is because users are less likely to be critical of $/ \mathrm{r} /$ bangtan to me due to the perceived power imbalance.

\section{Literature Review}

Although /r/bangtan identifies itself as a fandom community, scholarly definitions of fandom continue to evolve. Early publications, or the "first wave" of fandom studies, defined fandom in relation to physical spaces and objects since social media was not widespread yet, and combatted the negative narratives surrounding fans at the time (Cavicchi, 1998; Jenkins, 1992). However, recent work on digital fandom shows how the negative valence of "fan" has declined with the rise of social media, since everyone has "followed" or "liked" something before (Baym et al., 2017). In fact, how scholars describe fandom structures has diversified as well, from concepts related to Bourdieu such as subcultural capital (Hebdige, 1979) and the cultural economy of fandom (Fiske, 1992), to ideas such as an imagined community (Anderson, 1983), interpretive community (Lindlof, 2015), affinity spaces (Gee, 2005), fan world (Hills, 2017), and the concept of the public (Warner, 2002). Along the same lines, recent research has illuminated the fact that the diversity of social media platforms makes a fandom's dynamics and organization different on each platform (Morris, 2018), making each approach useful for analyzing different platforms. Likewise, in this paper, I build on Bourdieu's concept of social capital (1984) to 
describe the organization of the digital Anglophone BTS fandom that is unique to Reddit's hierarchical space. I expand upon social capital to describe how a moderators' position within the Reddit hierarchy allows them to function as a fandom gatekeeper.

Fandom studies scholarship has widely utilized Bourdieu's theory of social capital. Some scholars have cautioned against indiscriminately adopting Bourdieu's work to fandom studies, as it risks assuming that a fandom's organization is exclusively caused by class distinctions (Duffett, 2013). Others would agree, but emphasize the usefulness of Bourdieu's theories in discussing fan communities' social hierarchies, wherein fans compete over knowledge, access to the object of fandom, and status (Chin, 2018). In addition, scholars have noted that fandom hierarchies are neither static nor monolithic, as they vary between platforms and are constantly contested by other fans trying to move upwards in the hierarchy by gaining fandom knowledge and reputation (Chin, 2018; MacDonald, 1998). Although this idea of fandom hierarchy is useful for rhizomatic social media platforms, in this paper I show that within visibly hierarchical digital spaces like Reddit, we can see those at the top of the hierarchy—often moderators or administrators - as having unlimited, uncontested social capital that does not rely on their knowledge or reputation. Instead, moderators' social capital comes from their ability to control community discourse and their ability to appear unbiased to the community, as I will show.

Outside of general fandom studies, digital K-pop fandom research has grown over the past several years, with a focus on rhizomatic platforms. Scholars have conducted several studies of K-pop fandom within Asia (Kim and Kim, 2017; Sutton, 2018). Ethnographic studies of K-pop fandoms outside of Asia and the Anglosphere have grown too (Han, 2017; Min et al., 2019; Otmazgin and Lyan, 2019), as well as Anglophone K-pop fandom ethnographies (Abd-Rahim, 2019; Chang and Park, 2019; Yoon, 2019). However, recent research on 
Anglophone K-pop fandom and fandom studies in general has focused on fandom in rhizomatic social media spaces such as Twitter or Tumblr, believing fan-moderated spaces such as forums or LiveJournal pages are products of the past (Chin, 2018). In contrast to the above, this paper seeks to address the lack of research on explicitly hierarchical social media fandoms. Hierarchical social media platforms are important to fully understand how moderators gatekeep information into transcultural spaces like/r/bangtan, and therefore influence what parts of Hallyu content crosses over from the East to the West.

Political gatekeeping theory, not to be confused with fan studies "gatekeeping" (see: Scott, 2019), is often applied to traditional political news media rather than digital fandom communities. In the traditional sense, a gatekeeper's role is to decide how and what news to report, which will “determine what becomes a person's social reality, a particular view of the world," (Shoemaker and Vos, 2009: 3). We often conceptualize this view as a lone news editor deciding what stories to report within a physical newspaper's limited space. However, with the rise of social media, some might argue that traditional gatekeeping is dead due to the vast amounts of information now available. But some scholars have noted that although "many, many media gates exist... audiences attend to a relatively small percentage of those gates," (Vos, 2015: 11) demonstrating that most people do not want to verify information across multiple sources. Instead, most prefer a single trustworthy gatekeeper to curate the most important information for them (Heinderyckx, 2015: 263). My research on /r/bangtan supports this, as users explicitly prefer/r/bangtan because of the moderators' gatekeeping of BTS news. Moderators' gatekeeping thus shapes the users" "social reality" of the object of fandom, as I will discuss.

Fandom curators, who "are more established fans...with deeper knowledge of, and access to, the fandom and its texts," use their familiarity to introduce newer fans to a fandom (Kompare, 
2017: 107). Fandom curators are similar to political news gatekeepers, albeit confined to their fandom space. This is because fandom curators, much like a political gatekeeper, decide what information to expose to new fans and when, thereby "shaping the audience's thoughts about what the world is like," the "audience" being the new fans, and the "world" being the object of fandom (Shoemaker and Vos, 2009: 3). To elaborate, fandom studies scholar Derek Kompare explains: "a curated museum exhibit affects ways in which visitors understand the objects displayed, curated fan experiences shape how fans understand and engage with a text and fandom that is new to them," (Kompare, 2017: 108). In hierarchical fandom spaces like /r/bangtan, the moderators shape the community's attitudes towards the object of fandom because they are the sole, unchallenged fan curators. Although users can access outside rhizomatic spaces to find news forbidden from /r/bangtan, most would prefer for one trustworthy source to determine what information is the most important to know, as in political gatekeeping (Heinderyckx, 2015: 263). Users generally do not want to spend time sorting through the plethora of disorganized content available on rhizomatic sites to find BTS news, as I will discuss. However, the /r/bangtan moderators' ability to shape fans' perceptions and influence the East-West flow is not just from gatekeeping — it is also specifically because $/ \mathrm{r} / \mathrm{bangtan}$ is a transcultural fandom.

I use the term transcultural over transnational fandom because $/ \mathrm{r} /$ bangtan users have no inherently unifying traits beyond being English-speakers, BTS fans, and Reddit users, which are "but one in a constellation of contexts" that might inform any one user's affinity for BTS (Chin and Morimoto, 2013: 93). In a transcultural fandom like/r/bangtan, gatekeeping's effect is doubled, because linguistic, geographic, and cultural barriers limit the average transcultural fan's ability to find information on their object of fandom. Therefore, the fans or spaces that can 
conveniently access, seek out, and curate information on the object of fandom are doubly influential on newer fans' attitudes. Further, unlike traditional political news which has a plethora of competing news coverage (Vos, 2015), news outlets rarely cover transcultural fans' object of fandom because they originate and circulate outside of traditional Western media capitals' view. This makes spaces like /r/bangtan that can be a singular curated news source for a transcultural act like BTS even more influential in shaping fans' perceptions of BTS. Both of these points mean that the moderators of transcultural, hierarchical spaces like $/ \mathrm{r} / \mathrm{bangtan}$ greatly affect how their community's users will continue to interact with and spread Eastern media to the West, and thus shape the East-West flow.

The transcultural Anglophone K-pop fandom provides a way to de-center American and British media from fandom studies. Transcultural fandom scholars criticize fandom studies' focus on English-speaking (usually white) fans of American or British media, and the sidelining of overseas fandom to fandom studies' periphery (Morimoto, 2018). As other transcultural fandom scholars have noted, East Asian popular culture such as K-pop and anime illustrates a reversal of the usual center-periphery of fandom studies, wherein mostly white, English-speaking fans of Asian media occupy the transcultural periphery of a fandom (Chin et al., 2017; Morimoto and Chin, 2017). Digital Anglophone K-pop fandom presents the opportunity to study the unique insights a transcultural fandom can provide without language or distance barriers.

\section{Data Analysis and Interpretation}

\section{Demographics}

Including myself, I interviewed $8 / \mathrm{r} /$ bangtan moderators. All identified as female, and all but one used Reddit frequently before becoming a member of /r/bangtan. All were regular users of the $/ \mathrm{r} / \mathrm{bangtan}$ community for some time before becoming a moderator, ranging from half a 
year to two years. When interviewed, the time each respondent had been a moderator ranged from less than a year to over three years. Only half identified as native English speakers or bilingual (meaning they grew up speaking English and another language); the other half said English was their second language. Almost all of the moderators came from either the United States or Europe. The user-created posts I analyzed are public, meaning $/ \mathrm{r} / \mathrm{bangtan}$ is a community accessible to anyone with open internet regardless of membership. The rules page of the subreddit emphasizes this public accessibility (/r/bangtan wiki, 2020). However, posts the moderators have removed are not public and therefore are not included in this paper for ethical reasons.

Moderators' Daily Tasks

$\mathrm{A} / \mathrm{r} /$ bangtan moderator's most important, recurring task is gatekeeping the subreddit's news feed. When I asked my interviewees what their most common task was, all agreed that it was removing posts or comments that violate the community's established rules, such as "rumors" or "drama from another community," as listed on the rules page (/r/bangtan wiki, 2020). As one moderator elaborated:

Me: So, a lot of [moderation] is deciding what should be removed, would you say? Moderator \#1: I would think that's about $90 \%$ of the job with just the amount of removals we do in a day. The rest is keeping up with Bangtan [BTS] and reading/watching everything that's been submitted.

The moderators gatekeep the subreddit news feed for the users by removing posts and comments, affecting the flow of BTS information to their transcultural users. Therefore, deciding to remove a post is the most critical action $\mathrm{a} / \mathrm{r} / \mathrm{b}$ bangtan moderator can take. How a moderator decides which posts to remove impacts the gatekeeping of the subreddit and influences users' perceptions of BTS, therefore influencing the East-West flow. 
As mentioned, the moderators make the community's rules and removal decisions by "executive fiat". Users are rarely involved in the removal or rule creation process. For example, Moderator \#6 compared the post removal process to a judiciary panel, where the moderators discuss amongst themselves what should be removed:

This is going to sound way full of ourselves, but [the decision-making process] operates like a judicial panel.... The rules are the first level that guides what goes and what stays. But just like with any law, then there are things that are a bit more grey...We decide those by talking it out with the other mods and looking at precedent for what we've allowed or not allowed in the past....And then there are the things that are always about judgment calls. Even though we have some pretty well detailed rules, some of those rules by their very nature rely on the mods' judgment. For example... what is a difficult but valuable and constructive discussion. For those types of decisions, we talk as a group, look at the rules, and also look at the person posting. We have sub members that are very active every day and you get to know them. So you can look at a comment that might seem like trolling if it came from a complete stranger, but because it's from a regular member you can give them more of the benefit of the doubt and that weighs in to whether to remove or not if it's the type of removal that isn't black and white and requires a judgment call. The opposite is also true.

Not only can $/ \mathrm{r} /$ bangtan moderators veto content, they alone create and negotiate the very rules governing their decisions. As a potential counterexample, Moderator \#2 described a time when the moderators did ask for user input regarding a new fanart rule: "There were a lot of mixed opinions from the subscribers regarding all the fanart we featured, so we... asked how they suggested we would solve it. In the end, it was us who decided what we were going to do." Although the moderators asked for user input into the rule-creation process, the moderators ultimately made the decision themselves. This demonstrates that the moderators have the authoritarian ability to create, change, and enforce the rules, which grants them functionally unlimited control over the community's worldview, like a political gatekeeper. For these reasons, I say that in Bourdieu's terms, subreddit moderators have unlimited social capital within their community, as they alone control what community discourse and content is acceptable. But how do moderators maintain their unlimited social capital and stay well-liked among the community 
despite their authoritarian rule?

\section{Unbiased Perception \& Social Capital}

Since social connections are an integral way to gain social capital according to Bourdieu (1984), we would expect the moderators to personally communicate with the community often to gain these connections. However, remaining a well-liked moderator does not involve creating or maintaining individual social connections. In fact, almost all of the moderators I interviewed mentioned that they felt like they could not participate in the community like they did before becoming a moderator, thereby stunting their ability to accrue traditional social capital. The moderators said they felt this way because their comments were scrutinized for signs of potential bias, as Moderator \#6 elaborates (emphasis mine):

[Users] know you as a mod[erator] first and foremost and take your comments as representative of the whole mod team. It makes it really difficult to engage in the community to the same degree as before. Sometimes there are controversial discussions I want to weigh in on, but I don't. I understand why it's necessary...For the sub[reddit's users] to be able to trust the mod team when we make hard or unpopular decisions, they have to trust we're impartial. We try our absolute best to stay impartial and fair as a group, but how could anyone believe that if you have a mod jumping into one side of a debate? ... Once I became a mod, it sort of ended my ability to engage with the community in a personal way.

This response indicates that the community perceiving the moderators as unbiased is integral to the peaceful functioning of $/ \mathrm{r} /$ bangtan's hierarchy. Instead of personal social connections like in social capital, the important thing for a moderator is having the interpersonal skills to act or at least appear unbiased to the community. The moderators of /r/bangtan are similar to the "neutral" type of moderator described by Seering et al., who felt that suspected bias would hinder their moderator credibility (1426). The moderator's place in the hierarchy remains unchallenged so long as the moderator appears unbiased when enforcing rules, which makes the moderators' gatekeeping influence on fans' perceptions of BTS more impactful.

As a disclaimer, a moderator maintains their status even if they do appear biased because 
users cannot forcibly revoke a moderator's position. However, with this, moderators "must be careful not to overplay their hand in seeking to inculcate a particular kind of space or else they risk losing users who can simply go elsewhere if they no longer enjoy a particular subreddit," (Squirrell, 2019: 1913). So, while a moderator's social capital is technically unlimited, it is in the moderators' best interest to remain on good terms with their users to grow the community (and maintain their social capital). To clarify, although growing the community does increase the moderators' social capital by giving them control over more fans' perceptions, I believe that the /r/bangtan moderators primarily want to grow their community because they want to create a positive, open discussion space for their fellow fans, making the increase in social capital an unintended side-effect. I believe this explanation is more relevant because the $/ \mathrm{r} / \mathrm{bangtan}$ moderator application process favors applicants with a passion for the community, which my interviews confirm. However, even if the moderators' intentions are good, the moderators still rule over /r/bangtan in a benevolently authoritarian manner. This authoritarian rule, no matter how benevolent, can foster a space that might ignore potential sources of cultural or racial fandom conflict, particularly in a transcultural fandom. If the community is benevolently authoritarian, one questions why a regular user would want to join such a community.

\section{The Draw of Moderators as Gatekeepers}

Counterintuitively, /r/bangtan's benevolently authoritarian style of moderation is the very reason users prefer it. My interviews supported this and specified the subreddit's main advantages first as the moderators' gatekeeping of the news feed, which separates important new updates from unverified rumors, and second as the moderators' ability to protect users from potential cyberbullying. For example, Moderator \#6 explained that:

...having a mod team means you get more of a curated feed - a lot of the removals we do are almost editorial in nature, cutting out fluff, spam, or things that are poorly sourced or 
not true. That also sets it apart and I think is a nicer experience for sub members because most of the onus for that curation is on the mod team - not the sub members- to do. By contrast, on other platforms that's on the user to figure out who to follow, who to block, etc.

Moderators are the ultimate gatekeeper for determining what is worthwhile BTS content. For the people who use /r/bangtan as their primary source of BTS news, the moderators act as an information gatekeeper, curating the content able to reach and influence this section of the transcultural BTS fandom. If the moderators prohibit something on the subreddit, people who primarily use /r/bangtan for news and updates will not assign as much verified importance to it as something that is allowed on $/ \mathrm{r} /$ bangtan. This is because, as in political gatekeeping, the content "that gets through the gates are accorded the most importance by the audience and effects public opinion" (Shoemaker and Vos, 2009: 3). The moderators thereby influence the community's opinions and interactions with BTS by controlling the information flow, which is even more effective in a transcultural fandom where fans' information-gathering ability and mainstream news coverage is limited.

As an example, if a fan posted an account detailing a rude encounter with BTS, those who use $\mathrm{r} / \mathrm{bangtan}$ as their exclusive source of information would not be aware of this post, as "rumors" and "fan drama" are prohibited subjects on /r/bangtan. Any mention would be removed by the $/ \mathrm{r} /$ bangtan moderators. This would in turn effect the users' perception of BTS and the fandom (in this case, positively by omission). Even if these users saw this post on another platform, $/ \mathrm{r} /$ bangtan users are inclined to take it less seriously and scroll past because the post did not receive /r/bangtan's verification. This is because most users do not want to do the time-consuming process of seeking out and verifying content themselves. The lack of trusted, mainstream news sources for transcultural fandoms leaves fan communities like $/ \mathrm{r} / \mathrm{bangtan}$ to fill the void. In this sense, rhizomatic platforms are like tabloids, while /r/bangtan is the reliable 
fandom newspaper. This gives the /r/bangtan moderators the power to determine what is "real" or "fake" news for its users, and thereby influence fans' attitudes, as political gatekeepers do.

While the moderators consistently mentioned gatekeeping as /r/bangtan's primary draw, another advantage is cyberbullying protection. This is how Moderator \#5 described the advantages of $/ \mathrm{r} /$ bangtan over other platforms:

Most other BTS fandom spaces are either entirely unmoderated or loosely moderated.... the moderation appeals to fans who prefer to interact in the fandom without certain negative baggage that usually comes with unmoderated platforms - e.g. rude and hostile behavior, rumors/gossip, trolling, excessive low-effort content, etc.

Moderator \#5 directly mentions the rhizomatic nature of other social media platforms as a weakness compared to /r/bangtan's institutionally hierarchical structure, specifically in the control over fan interactions. Rhizomatic social media platforms may seem to have less strictly regulated speech, however, less regulated speech brings with it problems like mob rule and digital populism (Kim, 2008). Internet anonymity exacerbates these drawbacks and increases the potential for internet hate mobs to form. Moderators can use their unlimited, permanent social capital as a barrier against cyberbullying by banning users who engage in personal attacks or trolling from the subreddit. This distinguishes /r/bangtan from rhizomatic social media platforms and allows them to control the subreddit's discourse, for better or for worse.

In sum, the moderators describe the draw of /r/bangtan as two main things: the moderators' ability to gatekeep content and prevent cyberbullying. While both reasons sound plausible for someone to prefer an openly authoritarian, hierarchical platform over a rhizomatic one, we have to wonder if the users themselves actually believe the moderators do a good job of gatekeeping. If not, there would be no reason for users to frequent the community.

\section{Users' Opinions of the Moderators}

In order to determine users' thoughts about/r/bangtan's moderation, I analyzed regular 
$/ \mathrm{r} /$ bangtan users' public comments made in response to topics created for community feedback or engagement (such as community announcements or rule update posts). Although the type of users that interact with these posts are likely the most active and engaged in the community, these are also the users most likely to voice concerns about any questionable moderation actions. The vast majority of moderator announcement posts I saw had comments praising the moderators. I focused on two main subreddit threads to determine users' general feelings towards the moderators: one moderator-created thread celebrating /r/bangtan's 6th anniversary, and one user-created thread suggesting that the moderators implement a less authoritarian feature on the subreddit. The first thread demonstrates typical comments the users make about the moderators, and the second thread demonstrates how the community responds to a request for less hierarchy in such an authoritarian community.

In general, users' comments about the moderators on $/ \mathrm{r} /$ bangtan's 6 th anniversary post were positive, praising the moderators with specific reference to gatekeeping. One such example of a user comment praises the moderators for keeping the subreddit a safe, organized space that any new fan can use to familiarize themselves with BTS. The comment goes on to express that the user feels they were "raised right" as a new fan, and "guided" to be a model BTS fan. The user finishes by stating they believe they wouldn't have the same "perception, depth, and maturity" as a fan if they participated on any other social media platform (r/bangtan, 2020). The user starts the comment by thanking the "mods" and then changes to thanking "the subreddit," referring to the community of the subreddit. However, "the subreddit" also refers to the moderators, since they shape the overall culture, rules, and discussion style of the subreddit (Squirrell, 2019) with their gatekeeping abilities. When this user describes being "guided" by the subreddit, the user references the moderators' news feed curation changing their "perception" of 
what is worthy content to engage with, similar to how gatekeepers influence people's perceptions of the world (Shoemaker and Vos, 2009). Hierarchical transcultural fandoms like /r/bangtan compound this influence over a fan's "perception" due to linguistic, geographic, and cultural information barriers and lack of alternative news aggregation sources. The "depth" and “maturity" the user gained from the subreddit references the moderators' gatekeeping of subreddit discourse, as the rules of /r/bangtan only allow the users to conduct themselves in a more "mature" manner, unlike social media platforms with less regulated speech. This comment shows how the users generally align with the opinions of the moderators on what makes the /r/bangtan community appealing. It demonstrates that /r/bangtan users want someone perceived as unbiased to control what content they engage with.

On the other hand, another post made by a regular user suggests a policy of monthly "town halls," where users can bring up their grievances with the rules or any other subreddit issues publicly. In other words, the user asks for less hierarchy in a strictly authoritarian community. The user even states in the original post that BTS advocates against authoritarianism, and questions why /r/bangtan wouldn't follow that example (r/bangtan, 2019a). This reason for the proposed policy clearly challenges the hierarchical nature of Reddit as a platform and the general authority of the /r/bangtan moderators. The community's response to this post was largely negative, with most users expressing that the moderators ran things satisfactorily. In the most-upvoted comment of the thread, one user responds that while they are not opposed to the idea, they believe that how the moderators operate is "effective" and doesn't need to change ( $r$ /bangtan, 2019b). Even when /r/bangtan was presented with open opposition to the moderators and given a less hierarchical alternative, users still supported the subreddit's hierarchical, authoritarian structure. The users want the moderators to rule in a benevolently 
authoritarian way, provided the moderators are perceived as unbiased when gatekeeping information and keep the subreddit discourse "mature" by controlling fan interactions.

Some might question the uncritical support of the moderation team as the result of self-selection: users choosing to remain in the community do so because they agree with the actions the moderators take, while users who disagree with the moderators leave for another type of social media. I agree fully; those who disagree with the moderators' actions do often leave (or are banned) and go to another platform, as other scholars have noted (Squirrell, 2019). However, I would argue that the fact that over 145,000 subscribed users voluntarily deciding to use /r/bangtan and affirm the moderators' gatekeeping is notable. The sheer number of people in the /r/bangtan community, which is the largest English-language BTS forum, suggests a desire for a polite, gatekept fandom space like /r/bangtan. The moderators' information gatekeeping and discourse policing provide an appealing alternative to the rhizomatic Internet's "signal-to-noise ratio" of unverified information and opinions that is "bad and getting worse," (Kollock, 2002: 219) and that becomes worse still in a transcultural fandom due to information-gathering barriers. A space like $/ \mathrm{r} /$ bangtan proves that there are people who want gatekept information, rather than listening to the disorganized opinions available on other platforms. The gatekeepers who direct information, then, effect what content from the East-West flow will reach and influence their audience, particularly in a transcultural setting like /r/bangtan.

\section{Conclusion}

Visibly hierarchical social media communities influence the trajectory of the larger East-West cultural flow. In the case of /r/bangtan, a transcultural digital Anglophone K-pop fandom space, we can see the details of how a hierarchical platforms' influence works in a transcultural setting. Volunteer subreddit moderators shape their community through their 
executive ability to gatekeep content through the creation and enforcement of the rules. Like a traditional gatekeeper, moderators are able to shape the /r/bangtan community's perceptions of BTS by gatekeeping the community's information flow. The moderators' control over /r/bangtan users' perception and engagement with BTS is enhanced since transcultural BTS fans' ability to find information about BTS is hindered by linguistic, geographic, and cultural barriers and lack of mainstream news sources. Therefore, moderators of transcultural fandoms such as $/ \mathrm{r} / \mathrm{bangtan}$ influence how and what Eastern content their users will continue to interact with, perceive, and further spread along this East-West flow. This thereby challenges both the major Eastern and Western media circuits' control over BTS' meaning-making, following trends on other platforms (Johnson, 2017). This paper demonstrates how /r/bangtan challenges the core-periphery of global media flows, but it also highlights how predominantly Western, English-speaking fans shape the transcultural flow of BTS fandom.

Moderators determine what is acceptable discourse for the community through their ability to create and enforce the rules. Since moderators control community discourse, we can see them as having unlimited social capital within their community. Due to this monopoly on the rules and enforcement, /r/bangtan is ruled in an authoritarian manner. However, although we might expect the authoritarian nature of the subreddit to be unappealing to users, it is why users prefer $/ \mathrm{r} /$ bangtan. Users want someone to gatekeep the news and prevent cyberbullying so they do not have to. For this reason, moderators maintain their unlimited social capital and remain on friendly terms with the community so long as they are perceived as unbiased. Because the users who prefer to use r/bangtan also prefer for the moderators to decide what content they should care about, the moderators are also necessarily gatekeeping what content from the East-West media flow is allowed to reach and influence this segment of the transcultural fandom. The 
number of users who prefer an expertly curated, seemingly unbiased space like /r/bangtan also indicates that there is a substantial desire for perceived unbiased gatekeepers to filter out "fake news" and other unverified content widely circulating on rhizomatic platforms. Research about the role and structure of transcultural hierarchical fandoms like /r/bangtan allows us to understand more of the mechanisms that make the East-West flow possible.

Further studies could analyze different transcultural hierarchical fandom spaces, whether on Reddit or a different social media platform, to see if the findings in this paper apply to other transcultural hierarchical fandom spaces. They could also address non-native English speakers or users from non-Western countries in these Anglophone, Western fandom spaces. Further research could also address how fans interact with and use differently structured social media sites for different purposes. This paper did not have space to adequately address the potential for racial and cultural conflicts in hierarchical, transcultural spaces like /r/bangtan, however, future research could build on this article to do so. Finally, future research can explore with more nuance the effect of a transcultural fandom on BTS' global popularity. 


\section{Bibliography}

Abd-Rahim A (2019) Online fandom: social identity and social hierarchy of Hallyu fans. Journal for Undergraduate Ethnography 9(1): 65-81. DOI: 10.15273/jue.v9i1.8885.

Anderson B (1983) Imagined Communities: Reflections on the Origin and Spread of Nationalism. Revised edition. London; New York: Verso.

Aurora (2019) Just using the name is a jackpot...5.6 trillion won 'BTS economy'. Chosun Ilbo, 25 June. Seoul, South Korea. Available at:

https://n.news.naver.com/article/023/0003456140 (accessed 30 March 2020).

Baym N, Cavicchi D and Coates N (2017) Music fandom in the digital age. In: Click MA and Scott S (eds) The Routledge Companion to Media Fandom. 1st ed. New York; London: Routledge, Taylor \& Francis Group, pp. 141-152. DOI: 10.4324/9781315637518-18.

Bourdieu P (1984) Distinction: A Social Critique of the Judgement of Taste. Cambridge, Mass: Harvard University Press.

BTS Projects Team (2019) Boy meets r/bangtan, vol 3., 2018: 3rd annual subreddit census. 18 October. /r/bangtan Projects Team. Available at: https://drive.google.com/file/d/1f2xZYOZU1R86YpmOc5GUf-JZtaMhHtaF/view (accessed 19 March 2020).

Cavicchi D (1998) Belonging together: fandom, community, and connection. In: Tramps Like Us: Music \& Meaning Among Springsteen Fans. New York: Oxford University Press, pp. $158-183$.

Chang W and Park S-E (2019) The fandom of Hallyu, a tribe in the digital network era: the case of ARMY of BTS. Kritika Kultura 32: 260-287.

Chin B (2018) It's about who you know: social capital, hierarchies, and fandom. In: Booth P (ed.) A Companion to Media Fandom and Fan Studies. 1st ed. Hoboken, NJ: John Wiley \& Sons, Inc., pp. 243-255.

Chin B and Morimoto LH (2013) Towards a theory of transcultural fandom. Participations: Journal of Audience \& Reception Studies 10(1): 92-108. DOI: http://dx.doi.org/10.17613/M6RP98.

Chin B, Punathambekar A and Shresthova S (2017) Advancing transcultural fandom. In: Click MA and Scott S (eds) The Routledge Companion to Media Fandom. 1st ed. New York; London: Routledge, Taylor \& Francis Group, pp. 298-306. DOI: 10.4324/9781315637518-36.

Duffett M (2013) Understanding Fandom: An Introduction to the Study of Media Fan Culture. New York: Bloomsbury. 
Elberse A and Woodham L (2020) Big Hit Entertainment and Blockbuster Band BTS: K-Pop Goes Global. 520-125, Case study, 8 June. Harvard Business School. Available at: https://store.hbr.org/product/big-hit-entertainment-and-blockbuster-band-bts-k-pop-goesglobal/520125?sku=520125-PDF-ENG.

Fiske J (1992) The cultural economy of fandom. In: Lewis LA (ed.) The Adoring Audience: Fan Culture and Popular Media. London; New York: Routledge, pp. 30-49.

Gee JP (2005) Semiotic social spaces and affinity spaces: from The Age of Mythology to today's schools. In: Barton D and Tusting K (eds) Beyond Communities of Practice. 1st ed. Cambridge: Cambridge University Press, pp. 214-232. DOI: 10.1017/CBO9780511610554.012.

Gillespie T (2018) Custodians of the Internet: Platforms, Content Moderation, and the Hidden Decisions That Shape Social Media. New Haven: Yale University Press.

Han B (2017) K-Pop in Latin America: transcultural fandom and digital mediation. International Journal of Communication 11: 2250-2269.

Hebdige D (1979) Subculture: The Meaning of Style. London; New York: Routledge. Available at: http://www.123library.org/book_details/?id=67205 (accessed 22 February 2020).

Heinderyckx F (2015) Gatekeeping theory redux. In: Vos TP and Heinderyckx F (eds) Gatekeeping in Transition. New York; London: Routledge, Taylor \& Francis Group, pp. 253-267.

Hills M (2017) From fan culture/community to the fan world: possible pathways and ways of having done fandom. Palabra Clave - Revista de Comunicación 20(4): 856-883. DOI: 10.5294/pacla.2017.20.4.2.

Hindman MS (2009) The Myth of Digital Democracy. Princeton: Princeton University Press.

Jenkins H (1992) Textual Poachers: Television Fans \& Participatory Culture. Studies in culture and communication. New York: Routledge.

Jin DY (2016) New Korean Wave: Transnational Cultural Power in the Age of Social Media. Urbana, Chicago: University of Illinois Press.

Jin DY (2018) An analysis of the Korean wave as transnational popular culture: North American youth engage through social media as TV becomes obsolete. International Journal of Communication 12: 404-422.

Jin DY and Yoon K (2016) The social mediascape of transnational Korean pop culture: Hallyu 2.0 as spreadable media practice. New Media \& Society 18(7): 1277-1292. DOI:

$10.1177 / 1461444814554895$. 
Johnson D (2017) Activating activism: Facebook trending topics, media franchises, and industry disruption. Critical Studies in Media Communication 34(2): 148-157. DOI: 10.1080/15295036.2017.1298142.

Kim M-S and Kim H-M (2017) The effect of online fan community attributes on the loyalty and cooperation of fan community members: the moderating role of connect hours. Computers in Human Behavior 68: 232-243. DOI: 10.1016/j.chb.2016.11.031.

Kim Y (2008) Digital populism in South Korea? Internet culture and the trouble with direct participation. Korea Economic Institute 3(8). Academic Paper Series: 1-8.

Kollock P (2002) The economies of online cooperation: gifts and public goods in cyberspace. In: Communities in Cyberspace. London; New York: Routledge. Available at: http://public.ebookcentral.proquest.com/choice/publicfullrecord.aspx?p=168601 (accessed 1 May 2020).

Kompare D (2017) Fan curators and the gateways into fandom. In: Click MA and Scott S (eds) The Routledge Companion to Media Fandom. 1st ed. New York; London: Routledge, Taylor \& Francis Group, pp. 107-113. DOI: 10.4324/9781315637518-14.

Lindlof TR (2015) The interpretive community redux: the once and future saga of a media studies concept. In: Lind RA (ed.) Produsing Theory in a Digital World 2.0. New York, NY: Peter Lang US, pp. 19-39. DOI: 10.3726/978-1-4539-1629-2.

MacDonald A (1998) Uncertain utopia: science fiction media fandom and computer-mediated communication. In: Harris C and Alexander A (eds) Theorizing Fandom: Fans, Subculture, and Identity. The Hampton Press communication series. Cresskill, N.J: Hampton Press, pp. 131-152.

Min W, Jin DY and Han B (2019) Transcultural fandom of the Korean wave in Latin America: through the lens of cultural intimacy and affinity space. Media, Culture \& Society 41(5): 604-619. DOI: 10.1177/0163443718799403.

Morimoto L (2018) Transnational media fan studies. In: Scott S and Click MA (eds) The Routledge Companion to Media Fandom. New York; London: Routledge, Taylor \& Francis Group, pp. 280-289.

Morimoto L and Chin B (2017) Reimagining the imagined community: online media fandoms in the age of global convergence. In: Gray J, Sandvoss C, and Harrington CL (eds) Fandom, Second Edition: Identities and Communities in a Mediated World. 2nd ed. New York; London: NYU Press, pp. 174-188. DOI: 10.2307/j.ctt1pwtbq2.

Morris JW (2018) Platform fandom. In: Scott S and Click MA (eds) The Routledge Companion to Media Fandom. New York; London: Routledge, Taylor \& Francis Group, pp. 356-365.

Otmazgin N and Lyan I (2019) Fan entrepreneurship: fandom, agency, and the marketing of Hallyu in Israel. Kritika Kultura 32: 288-307. 
r/bangtan (2019a) Open letter: town hall for r/bangtan. Text Post. Available at:

https://web.archive.org/web/20200309194238/https://www.reddit.com/r/bangtan/commen ts/bvluy4/open_letter_town_hall_for_rbangtan/(accessed 23 March 2020).

r/bangtan (2019b) Open letter: town hall for $r$ /bangtan. Post Comment. Available at: https://web.archive.org/web/20200309194238/https://www.reddit.com/r/bangtan/commen ts/bvluy4/open_letter_town_hall_for_rbangtan/(accessed 23 March 2020).

r/bangtan (2020) /r/bangtan's 6th anniversary! Post Comment. Available at: https://web.archive.org/web/20200330150733/https://www.reddit.com/r/bangtan/commen ts/en8dyz/rbangtans_6th_anniversary/fdwfed3/(accessed 23 March 2020).

/r/bangtan wiki (2020)/r/bangtan Rules. Available at: https://www.reddit.com/r/bangtan/wiki/rules (accessed 17 April 2020).

Scott S (2019) Interrogating the Fake Geek Girl: The Spreadable Misogyny of Contemporary Fan Culture. In: Fake Geek Girls. NYU Press, pp. 76-108. DOI: $10.18574 / \mathrm{nyu} / 9781479838608.003 .0004$.

Seering J, Wang T, Yoon J, et al. (2019) Moderator engagement and community development in the age of algorithms. New Media \& Society 21(7): 1417-1443. DOI: $10.1177 / 1461444818821316$.

Shim D (2008) The growth of Korean cultural industries and the Korean wave. In: East Asian Pop Culture: Analysing the Korean Wave. Hong Kong: Hong Kong University Press, pp. 15-32. Available at:

http://ebookcentral.proquest.com/lib/uhm/detail.action?docID=677282 (accessed 25 November 2019).

Shoemaker PJ and Vos TP (2009) Gatekeeping Theory. New York: Routledge.

Squirrell T (2019) Platform dialectics: the relationships between volunteer moderators and end users on Reddit. New Media \& Society 21(9): 1910-1927. DOI: $10.1177 / 1461444819834317$.

Stoycheff E, Liu J, Wibowo KA, et al. (2017) What have we learned about social media by studying Facebook? A decade in review. New Media \& Society 19(6): 968-980. DOI: $10.1177 / 1461444817695745$.

Sutton RA (2018) Tracking the Korean wave in transnational Asia: K-Pop and K-Pop fandom in Indonesia. Asian Musicology 28: 9-39.

Théberge P (2005) Everyday fandom: fan clubs, blogging, and the quotidian rhythms of the Internet. Canadian Journal of Communication 30(4). Available at: https://cjc-online.ca/index.php/journal/article/view/1673/1810 (accessed 31 January 2020). 
TooFab Staff (2017) 'Who the hell is BTS?' The band who beat Bieber, Ariana, Selena and Shawn. TooFab, 22 May. Available at:

https:/toofab.com/2017/05/22/who-the-hell-is-bts-this-is-the-band-who-beat-bieber-arian a-selena-and-shawn/usic.

Vos TP (2015) Revisiting gatekeeping theory during a time of transition. In: Vos TP and Heinderyckx F (eds) Gatekeeping in Transition. New York; London: Routledge, Taylor \& Francis Group, pp. 3-24.

Warner M (2002) Publics and counterpublics. Public Culture 14(1): 49-90.

Yoon K (2019) Transnational fandom in the making: K-pop fans in Vancouver. International

Communication Gazette Jin DY (ed.) 81(2): 176-192. DOI: 10.1177/1748048518802964. 